\title{
Soberanía: una nueva forma de contener y administrar la violencia
}

\author{
María Rosario SERRANO GARCÍA
}

\begin{abstract}
RESUMEN:
La soberanía no sólo era una teoría para el buen ordenamiento de un estado sino una forma de anular la autonomía del espíritu profético y someterlo a la dialéctica del estado y a los intereses de los gobiernos. La soberanía implica que no existe ninguna fuerza que opere al margen del poder capaz de regenerar o traer la salvación a un pueblo corrupto. La soberanía supone la creación de un espejismo, la manifestación del espíritu libre del pueblo es un producto o invención del poder estatal. La homogeneización y despersonalización del pueblo no es el resultado de la lucha por conquistar la libertad y la igualdad, sino el intento de que esta libertad e igualdad no suponga el desmoronamiento de la fuerza imperial.
\end{abstract}

PALABRAS CLAVE: soberania, profecia, revolución, violencia

\begin{abstract}
:
Sovereignty was not only a theory for the proper law of a State but a way of taking away the autonomy of the prophetic spirit and subject to the dialectics of state and government interests. Sovereignty implies that there is no force that operates outside the power capable of regenerating and bring salvation to a people corrupt. Sovereignty involves the creation of a mirage, the manifestation of the free spirit of the people is a product or invention of state power. The homogenization and depersonalization of the people is the result of the struggle to gain freedom and equality, but the intent for this freedom and equality does not entail the collapse of imperial force.
\end{abstract}

KEYWORDS: sovereignty, prophecy, revolution, violence

\section{De la monarquía a la soberanía}

En el tránsito de la Edad Media a la Edad Moderna, contemplamos el surgimiento de una nueva forma de contener la violencia. A lo largo de la Edad Media podemos apreciar dos modalidades o aplicaciones de la violencia, la violencia ejercida entre dos iguales o entre súbditos y la ejercida entre los súbditos y los monarcas o delegados. La primera modalidad, la violencia ejercida entre dos iguales es horizontal y se mueve en las dos direcciones, de uno al otro y del otro al uno. Sin embargo la violencia ejercida entre dos individuos de distinto rango es diferente, pues requiere un movimiento ascendente o descendente $y$, por tanto, la capacidad de ejercer violencia del uno sobre el otro no es similar, la violencia que ejerce el monarca sobre el súbdito tiene un carácter de totalidad, de la que carece la violencia del súbdito al soberano.

Nos centraremos en esta violencia ascendente y descendente que se ejerce entre súbdito y soberano. Estudiaremos algunas de sus líneas maestras y cómo el «estado moderno» intenta neutralizar la protesta ciudadana para perpetuarse y salir indemne de su 
empuje. Recordaré que en las formulaciones iniciales del «estado moderno» está presente la problemática de las Guerras Religiosas y el intento de neutralizarlas, a través de la construcción de estados fuertes que operan al margen de la legitimación divina. Veremos las soluciones propuestas por Hobbes y Spinoza.

La tesis que voy a defender en este trabajo es que el «estado moderno» nace con un propósito, el de generar mecanismos de control y limitación de la voluntad ciudadana para ejercer la violencia. La imposibilidad de las monarquías cristianas para contener la violencia de los súbditos, genera una nueva forma de organización, que se concretizará en los estados modernos, y se refinará en lo que Foucault llama la Sociedad Disciplinaria.

El «estado moderno» se enfrenta a la necesidad de contener dos tipos de violencia ciudadana:

El primer tipo, se refiere a la violencia ejercida mediante la transgresión de la ley en aras de provocar caos social. Esta forma de ejercer la violencia es muy limitada, pues pronto aquel que posee poder absoluto, como es el caso de los monarcas, aplaca rápidamente la ofensiva y la neutraliza con una violencia mayor, ejercida, en términos foucaultianos, desde el poder de decidir sobre la vida y la muerte.

El segundo tipo, se refiere a la violencia ejercida sobre el monarca a través de la profecía. La profecía se caracteriza porque está fuera del ámbito del poder, su discurso de aglutina en torno a un universal: la justicia, y tiene una estructura mesiánica, en cuanto que apela a una felicidad-redención final.

Esta fórmula va a ser utilizada a lo largo de la historia bajo distintas apariencias (reformadores, revolución francesa, revolución bolchevique...etc.), como un recurso contra el poder absoluto.

Benjamin en sus Tesis sobre la filosofía de la historia vincula este poder mesiánico a una memoria, la de los restos perdidos. Son esos restos perdidos los que siempre empujan a la redención. Los excluidos están condenados a vivir fuera de la fortaleza regia, y por tanto, sólo ejerciendo una violencia sobre sus límites pueden resucitar o volver a aparecer en el ámbito social.

Jean Bodin, en este sentido situará a los vagabundos y al monarca en la misma situación ontológica, ambos quedan fuera de la estructura, y de esta manera hará surgir un nuevo concepto, el de la soberanía (soberanía frente a monarquía, como veremos más adelante). 
Jean Bodin, lanza una pregunta: ¿están realmente los vagabundos sometidos a esta cadena de mando y obediencia? No lo están, precisamente por eso, porque son los olvidados. Y esta situación de olvidados, según indica Antonio Rivera en su artículo sobre Bodino $^{1}$, los convierte en los grandes enemigos del «estado». Sin embargo, para ser efectivos necesitan adherirse a algo que les procure la unidad de la que carecen, y este algo es la estructura mesiánica capaz de generar una estructura de poder en virtud de una promesa mesiánica, la redención.

La redención, en este sentido puede entenderse en un volver a aparecer en la esfera pública, porque como dice Benjamin a la injusticia física o social le sobreviene una mayor y es la hermenéutica ${ }^{2}$; la reparación de esta injusticia hermenéutica sólo puede surgir y darse en el entorno social. Hannah Arendt señalará que ya en el mundo griego no aparecer en la esfera pública significaba no formar parte de la comunidad política. Sin embargo, habrá que esperar a Maquiavelo, para que esta pertenencia a la comunidad política no dependa de la capacidad de aparecer en la plaza pública, sino de aparentar ser digno de ella. En este sentido por primera vez la representación adquiere autoría como generadora de poder. Es precisamente la imposibilidad de representarse, debido al control y monopolio de la representación por parte del poder, la que convierte al olvidado en una fuerza o poder que empuja a hacerse realidad.

Jean Bodin va a prefigurar ese nuevo concepto de soberanía que desarrollará Hobbes, consistente en que el soberano (ya no se le llamará monarca), detenta un poder que ya no está vinculado a una cadena de mando y obediencia que desciende de los cielos y se extiende al último de los hombres, como en las monarquías católicas, sino que se halla desligado de toda cadena humana y esto le procura el verdadero poder absoluto. La soberanía -escribirá Bodino- no es limitada, ni en poder, ni en responsabilidad ni en tiempo ${ }^{3}$. El soberano no puede ni debe obedecer a nadie nada más que a sí mismo. El verdadero poder soberano reside en esa desvinculación de la estructura social, por eso el único enemigo capaz de arrebatarle su poder es aquel que queda fuera de esa estructura, es decir los vagabundos. Bodin solo encuentra una solución, la de incorporar a estos enemigos a la cadena de mando y obediencia estatal, mediante la esclavitud. Lo cierto es que esta

\footnotetext{
${ }^{1}$ A. RIVERA GARCIA, La amenaza latente del vagabundo en la literatura politica del siglo XИ, Revista de Filosofia, n'10, 1995, 127-142

2 W. BENJAMIN, Tesis sobre la filosofía de la historia, Taurus, Madrid, 1973, 2-11

${ }^{3}$ J. BODIN, Los seis libros de la república, Trad. Pedro Bravo, Gala, Tecnos, 2010, 49
} 
solución no fue muy bien recibida, por lo que la fuerza del mesianismo profético siguió siendo un mecanismo activo y útil, para reconstruir los lazos de aquellos olvidados que fueron desprovistos de su poder no mediante el sometimiento sino mediante la exclusión.

La eficacia de la exclusión consiste en que los excluidos quedan totalmente aislados entre sí, de manera que a la incapacidad de pertenecer al poder por el cual han sido excluidos, se le suma la imposibilidad de pertenecer a ninguno otro poder emergido de entre ellos. Esta situación de aislamiento y soledad del excluido es tan radical que ningún olvidado puede portar poder profético alguno, sino que es menester que alguien que forme parte de la estructura de poder utilice la fuerza del profetismo mesiánico para rescatar lo olvidado y destrozar o romper los límites del «estado».

De esta estructura profética se sirvieron los reformadores para destrozar o acabar con las monarquías. Calvino o Lutero formaban parte del sistema, y sin embargo rescataron o aglutinaron a aquellos que sobrepasaban los límites de dicho «estado», confundiéndolos con aquellos que eran parte integrante de los muros estatales. Podríamos decir que las Guerras Religiosas participan de este fenómeno profético.

Los nuevos reformadores políticos, preocupados por cimentar un nuevo «estado» sin horizontes religiosos que pudieran ser conflictivos y excluyentes, se enfrentarán a la necesidad de reconstruir las bases del orden estatal sobre un suelo firme, es decir sobre una estructura unitaria y fuerte que hiciera frente a las amenazas del profetismo. Este es el caso de Hobbes, el cual retomando el nuevo concepto de soberanía de Bodin, lo lleva hasta límites insospechables. La estrategia consistía en acabar con el profetismo convirtiendo al propio «estado» en profético.

\section{La administración de la violencia en el «estado hobbessiano»}

Hobbes, convierte la propia estructura estatal en profética, situando el origen del «estado» en el apocalipsis, es decir en la posibilidad de la destrucción total. Hobbes aboga por un «estado» que es una respuesta ante la autodestrucción y diseña un poder absoluto capaz de poner orden en medio del caos. Más un poder así tan descomunal, sólo puede surgir de la unión y traspaso de la potencia o poder de todos los individuos a uno solo ${ }^{4}$. Es necesario

\footnotetext{
4 T.HOBBES, Leviathán o la materia, forma y poder de un estado eclesiástico y civil, Traducción, prólogo y notas de
} Carlos Mellizo, Alianza Editorial, Madrid, 2008, 159. 
que todos se desarmen a la vez, pero este desarmarse implica un acto de fe en la persona carismática. Dicha personalidad es la única capaz de sacar a los distintos individuos del estado de naturaleza regido por el tiempo histórico, donde la inexorabilidad de la autodestrucción es inevitable, e introducirlos en un nuevo «estado» creado ex nibilo, totalmente artificial, capaz de operar fuera del tiempo histórico.

La promesa profética emitida por el soberano consigue crear unidad y generar igualdad entre personas de distinto estatus, los cuales no comparten nada en común, en orden a una idea: un futuro deseable. La necesidad del apocalipsis hace imposible imaginar un futuro deseable al margen de la obediencia total a la propia persona del soberano. Sólo obedeciendo de forma incondicional al «Leviathán» podemos llegar a participar de un futuro, el cual sólo puede ser pensado y producido por un poder descomunal. La total imposibilidad de acceder a este futuro sin mediación del poder soberano, protege a tal potestad de toda crítica y rebelión, ya que éstas, sólo retrasarían la consecución del paraíso, atrayendo hacia sí el apocalipsis.

La soberanía hobbesiana, por tanto, se constituye en y a través de un acto de fe, mediante el cual todos deciden entregar sus armas a uno solo. De esta manera Hobbes controla la violencia ciudadana, pues desprovee de sentido a toda crítica. Cuando Moisés conducía a su pueblo hacia la tierra prometida, nadie estaba en disposición de verificar cual era el camino correcto a seguir; de la misma manera en cuanto el «Leviathán» produce un orden nuevo, no hay quien pueda enjuiciarlo, hasta que no se vislumbre el final del camino trazado por él.

\section{La soberanía diluida y la violencia dispersa en el TTP de Spinoza}

Frente al concepto moderno de soberanía prefigurado por Hobbes, Spinoza negará que tal concepto pueda referirse a la persona de un solo hombre. Spinoza dirá que sólo aquel capaz de la omnipotencia y omnipresencia, características de Dios, puede detentar la soberanía, configurando así lo que podemos llamar soberanía diluida. Spinoza, al contrario que Hobbes, anula la violencia del profetismo, introduciéndolo dentro de la marcha natural estatal, es decir, institucionalizándolo y por tanto convirtiéndolo en un mecanismo más al servicio del «estado». Para ello sitúa el origen del «estado» en las antípodas del 
apocalipsis, y así lo localiza en una experiencia positiva, que podría traducirse por: «juntos aumentamos nuestra propia potencia» $\aleph^{5}$. La comunidad política resultante no se constituye en virtud de la persona soberana, que salva del caos, sino de una ley que recoge la memoria o experiencia compartida del pueblo. La experiencia resultante de la convivencia a través de aciertos y errores, va a desencadenar unas leyes o expresiones de las conductas beneficiosas o perjudiciales para la vida en común.

Esta ley va ser la expresión más sublime de la justicia y de la equidad. Spinoza, que estudia el hecho profético dentro del pueblo hebreo, vincula el mensaje profético con el origen del «estado» y con el tiempo histórico. El mensaje profético se limita a invitar a los ciudadanos a retornar o actualizar ese momento primero o kairos donde la ley brillaba más que el sol, porque todos al unísono juraban amarla y observarla, tal y como ocurrió en el pueblo hebreo, en el proceso de constitución, a la salida de Egipto. Es labor profética frenar la fuerza de la corrupción siempre presente en todo proceso. No se trata de instaurar un paraíso como el de Hobbes que rompa el tiempo y viva al margen de éste, deteniéndolo a través de la incidencia de un poder soberano. Sino más bien se trata de impedir que el tiempo corrompa el paraíso logrado. El paraíso terrenal lo sitúa Spinoza en el origen de un pacto social justo, y por tanto se trata de un universo explorado por todos. No así como el paraíso hobbessiano, el cual sólo vive en la imaginación del soberano, y en los anhelos de una obediencia ciudadana. El paraíso de Spinoza es un paraíso compartido, producto de una ley vinculada a una memoria colectiva. En este sentido todos los ciudadanos saben comprender su presente desde su historia, y saben cuál es el futuro más deseable. Cumplirlo es tarea no de una voluntad soberana sino de todos y cada uno de ellos. La soberanía para Spinoza no reside en una única persona porque implica omnipotencia y omnipresencia. Ninguna persona humana puede controlar las acciones más recónditas del ser humano, o saber las injusticias cometidas bajo la oscuridad de la noche. Ningún ser humano puede estar en todos sitios a la misma vez y evitar los suburbios oscuros de la delincuencia callada. Ninguno, por sí solo. Sin embargo, la humanidad entera sí que está presente en todos y cada uno de los lugares. El ojo del ciudadano debe ser como el ojo divino, sensible a cualquier injusticia. Todo ciudadano aunque sea el más ínfimo de los seres posee la soberanía, una soberanía compartida. Spinoza dispersa la soberanía por todos los miembros de la comunidad política. Todos

${ }^{5}$ B. SPINOZA, Tratado Teológico Politico, Alianza editorial, Madrid, 2008, 158 
deben ser jueces de sí mismos y de los demás a la vez. Spinoza hace una transposición de la potestad divina a la potestad humana. Igual que el espíritu de Dios vivía esparcido por el pueblo de Israel, y el fenómeno profético no era más que una manifestación de ese espíritu libre. Así la soberanía se halla esparcida en cada corazón, y la profecía es el resultado del espíritu humano movido por la memoria del pueblo. No siendo esta memoria sino la experiencia más sublime de la libertad.

Spinoza acaba con la peligrosidad del fenómeno profético convirtiendo a todos los ciudadanos en profetas, y sometiendo este fenómeno a la racionalidad del «estado». Lo esencial del profetismo, en Spinoza, es que no puede romper ni dividir al «estado», sino que ha de contribuir a su regeneración interna, deteniendo la venida del apocalipsis. El «estado» debe hacer de katechon, según indica Koselleck, en su interpretación de los conceptos políticos. El profeta spinoziano nunca puede alzarse contra un gobernador o contra un sistema, sino solo y exclusivamente contra la ausencia de la ley. De esta manera Spinoza consigue someter un fenómeno tradicionalmente rupturista a la propia dialéctica del «estado».

\section{Conclusión}

Ambos, Hobbes y Spinoza, contienen la violencia producida por el fenómeno profético. Hobbes, estableciendo un «estado» proyectado hacia el futuro y por tanto exento de crítica. Spinoza dispersando la soberanía. Este dispersar la soberanía implica que el propio «estado» va a ejercer una violencia y control sobre los súbditos no mediante la fuerza impositiva de la persona soberana, sino a través de los distintos ciudadanos. Esto quiere decir que va a despersonalizar el agente ejecutor de la violencia y lo va a dispersar por entre los ciudadanos. Para concretizar y llevar a la práctica esta violencia diluida, habrá que esperar a Hegel, el cual marca el camino a través de las instituciones. Este, a mi modo de ver, va a ser el primer paso hacia la sociedad disciplinaria que define Foucault ${ }^{6}$.

Foucault dirá que el control sobre las personas se efectúa a través de las instituciones estatales, las cuales tienen la misión de ejercer la violencia sobre el individuo mucho antes de que trasgreda la ley, con el fin de evitar la criminalidad. En conclusión, la estructura del «estado moderno», tal y como lo hemos visto en Hobbes y Spinoza, se

${ }^{6}$ M. FOUCAULT, El nacimiento de la biopolitica, Annuaire du Colege de France, Paris, 1979, 367-372 
configura en un intento de disminuir la violencia ciudadana y aumentar el poder estatal. A este respecto, dice Hannah Arendt, criticando estas raíces, que el estado totalitario no hubiera sido posible sin el previo intento de la política moderna de aumentar el poder del «estado» a base de atomizar y controlar al individuo ${ }^{7}$.

Según el estudio expuesto, podríamos defender que, el «estado moderno» no se dedica a evitar la sublevación de los súbditos con la represión, como en la Edad Media; sino a través de un espejismo, produciendo él mismo dichas sublevaciones. El individuo piensa que es libre y puede revelarse contra la injusticia, pero dichas expresiones de libertad son producciones ilusorias del poder. En realidad el «estado» produce las manifestaciones de protesta y las aplaca, según considera. Después de esto ya no existe más violencia que la emitida desde la suprema potestad. Por fin el «estado» consiguió su sueño, el de ser como Dios, que juega con los hombres como si fueran marionetas. La producción ilusoria de libertad no hubiera sido posible sin la adquisición por parte del poder del mensaje profético, gracias a Hobbes, y sin la vinculación y sometimiento de ese mensaje a la propia dialéctica del «estado», gracias a Spinoza. Por fin el «como si no» de Pablo interpretado por Agamben ${ }^{8}$, adquiere todo su sentido. La redención consiste en anticipar la liberación humana, aunque ésta sólo pueda moverse en el mundo del pensamiento y no de facto.

\footnotetext{
${ }^{7}$ HANNAH ARENDT, Los orígenes del totalitarismo, Alianza Editorial, 2002, 369-382
}

8 AGAMBEN, El tiempo que resta, comentario a la carta a los romanos, Trotta, 2006, 60 